\title{
PERAN DIPLOMASI PERTAHANAN INDONESIA DALAM KERJASAMA PERTAHANAN INDONESIA DAN AMERIKA SERIKAT
}

\author{
Beni Sukadis \\ Lembaga Studi Pertahanan dan Studi Strategis Indonesia \\ bsukadis@gmail.com
}

\begin{abstract}
Abstrak
Tulisan ini memfokuskan pada hubungan diplomasi Indonesia dan AS dalam bidang politik dan pertahanan yang telah berjalan lama. Dinamika hubungan kedua negara sangat fluktuatif baik keeratan dan kedalaman kerjasama pertahanan. Kerjasama pertahanan bilateral dilakukan dalam rangka meningkatkan hubungan antara militer dan untuk meningkatkan profesionalisme TNI serta mencapai tujuan pertahanan negara Indonesia seperti menjaga kedaulatan dan integritas negara. Kepentingan Indonesia dalam menjalin kerjasama pertahanan dengan AS karena sebagian besar alat utama sistem senjata (alutsista) berasal dari AS dan negara-negara barat lainnya. Dengan mengambil perspektif pada masa pemerintahan Susilo B. Yudhoyono (SBY) tahun 2004-2014, maka diplomasi pertahanan sangat terkait erat dengan program Minimum Essential Forces (MEF) yang bertujuan membangun militer yang modern. Program MEF mendorong pemerintahan SBY untuk bekerjasama dengan AS dalam rangka pemeliharaan dan pembelian persenjataan yang mengalami embargo sejak tahun 1999. Disisi lain kegiatan kerjasama pertahanan Indonesia dan Amerika Serikat yang paling besar justru dalam bidang pendidikan dan pelatihan yaitu kursus singkat, pendidikan staf dan komando, seminar, pasca sarjana dan lain-lainnya. Sedangkan kerjasama pertahanan lain yang masih sangat minim hingga saat ini terutama dalam industri pertahanan. Penelitian ini menggunakan metode kualitatif dengan data dari sumber pustaka maupun wawancara dengan narasumber yang merupakan pelaku dan ahli di bidangnya serta sumber sekunder seperti buku, makalah dan bahan dari sumber terbuka lainnya.

Kata Kunci : diplomasi pertahanan, kerjasama pertahanan, MEF, Indonesia
\end{abstract}

\begin{abstract}
This research is focused on Indonesia-US diplomatic relations in politics and defense. The relationships are very volatile both in terms of closeness and depth of defense cooperation between the two countries. Bilateral defense cooperation is aimed at improving military relations between the two countries and building professionalism of the TNI - in addition to achieving the Indonesian defense goals such as maintaining the sovereignty and integrity of the country. Indonesia has interest in maintaining defense cooperation with the US due to the fact that the majority of Indonesia's major defense equipment is from the US and other western countries. By taking the perspective of the Susilo B. Yudhoyono administration (2004-2014), defense diplomacy is closely related to the Minimum Essential Force (MEF) program. The MEF program has initiated the Indonesian government to cooperate with the US in the context of maintenance and procurement of weapons that have been embargoed since 1999. This research also finds that among various defense cooperation activities between Indonesia and the US, the
\end{abstract}


major one is actually in the field of education and training, e.g., short courses, staff and command education, seminars, post graduate programs and others. Meanwhile, the other defense cooperation activity, namely defense industry, is still very minor until today. The method of research is qualitative using descriptive analytical collected from the interview of practitioners and from secondary sources such book, paper, and open sources.

Keyword: Defense Diplomacy, Military Cooperation, MEF, Indonesia

\section{Pendahuluan}

\section{Pembukaan Undang-Undang}

Dasar 1945 alinea ke-4 menyatakan bahwa Negara Indonesia memiliki tujuan nasional yaitu melindungi negara, mensejahterakan bangsa dan ikut mendukung ketertiban dunia yang berdasarkan kemerdekaan sebagai landasan dalam memperjuangkan kepentingan nasional. Menurut perspektif realis dalam teori ilmu Hubungan Internasional, negara adalah aktor utama dalam sistem internasional yang anarkis.Pencapaian utama kepentingan nasional suatu negara menurut Morgenthau (Weldes, 1997:278) adalah mempertahankan eksistensi dan menjaga keamanan atau melindungi negara dari ancaman negara lain dengan mengandalkan pada instrumen militer maupun diplomasi.Dalam menghadapi ancaman militer ataupun ancaman nonmiliter, Indonesia mengedepankan strategi pertahanan defensif aktif yang salah satunya ialah melalui diplomasi. Penggunaan instrumen diplomasi adalah hal yang lumrah dalam mencapai tujuan pertahanan negara yaitu melindungi kedaulatan negara, menjaga wilayah, serta melindungi warga negara. Diplomasi pertahanan yang dilakukan Indonesia adalah dalam rangka menjaga integritas nasional sekaligus juga menjaga stabilitas regional dan perdamaian dunia.

Semasa Orde Baru di bawah pemerintahan Presiden Soeharto, hubungan bilateral antara Indonesia dengan AS berjalan baik. Selain memiliki kepentingan bersama terkait ekonomi dan politik, kedua negara menganggap bahwa paham komunis merupakan ancaman di Asia Tenggara. Sehingga kerjasama militer Indonesia dengan AS semakin kuat. Hal ini ditandai dengan pengiriman personel militer Indonesia ke AS untuk mengikuti pendidikan di berbagai jenjang dengan tujuan meningkatkan profesionalisme militer seperti National Defense University, akademi perang (war college), sekolah staf komando, kursus singkat, dan seminar. 
Kerjasama militer kedua negara yang bersifat teknis yakni melalui Military Assistance Program (MAP) berakhir tahun 1978. Setelah itu, berdasarkan data dari Kemhan (2010), kerjasama militer kedua negara diwujudkan dalam beberapa program antara lain:International Military Education Training (IMET), Foreign Military Sales (FMS), dan Foreign Military Financing (FMF).Sejak rezim Orde Baru, AS menjadi sumber bagi persenjataan militer untuk Indonesia seperti pesawat tempur, pesawat angkut, radar, peralatan komunikasi, dan lain lain (McAslan, 2004).

Diplomasi antara pejabat pertahanan Indonesia dan AS semakin intens dilakukan saat Susilo Bambang Yudhoyono (SBY) menjabat sebagai Presiden RI. Dalam rangka mempererat hubungan kedua negara, Presiden SBY setidaknya telah mengunjungi AS sebanyak dua kali dalam periode I masa pemerintahannya dan dua kali dalam periode II. Sementara itu, Duta Besar RI untuk Amerika Serikat (1998-2001), Prof.Dorodjatun Kuntjoro-Jakti (Pohan, 2001) mengatakan Indonesia memiliki peran penting bagi AS karena dua hal. Pertama, AS senantiasa memiliki kepentingan ekonomi, perdagangan dan keamanan di Indonesia.Sedangkan Indonesia selalu bertindak sebagai aktor keamanan di kawasan Asia Tenggara. Kedua, meskipun Indonesia mengalami krisis ekonomi, perusahaan-perusahaan AS di Indonesia mendapatkan keuntungan dari sumber daya alam seperti emas, tembaga, minyak, gas, dan lain-lain. Pernyataan Dorodjatun ini semakin menegaskan bahwa Indonesia adalah mitra strategis bagi AS di kawasan Asia Tenggara. Dengan kata lain, keamanan dan kemakmuran Indonesia memiliki kontribusi langsung bagi kepentingan nasional AS.

Diplomasi pertahanan menjadi upaya penting untuk mempersiapkan kekuatan dengan berbagai kegiatan yang dilakukan Kemhan dalam mengusir musuh, membangun dan memelihara kepercayaan serta dalam pengembangan demokrasi. Pengamat militer Evan Laksmana menyatakan bahwa kerjasama pertahanan RI dan AS secara historis menjadi bagian penting dalam hubungan diplomatik kedua negara. Menurutnya, pada tingkatan tertentu kerjasama tersebut sangat baik dalam upaya membangun hubungan personal dan membentuk jejaring yang dapat mempererat kerjasama militer di masa yang akan datang [Laksmana, 31 Mei 
2016]. Menurut Kemhan sejak 1960-an sampai 2010, lebih dari 7000 personel militer Indonesia telah dikirim ke AS. Hal ini menunjukkan bahwa institusi militer AS memberikan kontribusi pendidikan yang besar bagi peningkatan kapasitas militer Indonesia.

Diplomasi pertahanan yang dilakukan Indonesia adalah dalam rangka memperkuat pertahanan negara sesuai amanat UUD 1945 dan UU seperti UU No. 3/2002 tentang Pertahanan Negara dan UU No. 34/2004 tentang TNI serta berbagai kebijakan pertahanan selama pemerintahan SBY. Dalam memperkuat pertahanan negara selama ini Indonesia sangat tergantung dari alutsista asing khususnya AS maupun negara barat lainnya, sehingga kerjasama pertahanan menjadi kata kunci dalam pembangunan pertahanan tersebut. Dengan paparan diatas maka tulisan ini akan membahas tentang upaya diplomasi pertahanan Indonesia berdampak pada kerjasama pertahanan antara Indonesia dan AS khususnya pada masa pemerintahan Susilo B. Yudoyono 2004-2014.

\section{Konsep Diplomasi pertahanan}

Menurut Mihal Marcel (2014)

konsep diplomasi pertahanan makin mengemuka pasca perang dingin yaitu sekitar pertengahan 1990an. Dalam perkembangannya instrumen militer kerap digunakan dalam pelaksanaan kebijakan luar negeri. Hal ini penting untuk mengatasi persoalan keamanan regional dan global terutama untuk menciptakan perdamaian yang langgeng. Menurut Marcel, konsep diplomasi pertahanan merupakan suatu upaya pengembangan kerjasama yang koheren di semua tingkatan dalam kerjasama antar negara di bidang keamanan dan militer dengan dampak yang riil. Dampak riil kegiatan ini berupa penguatan kelembagaan, pengembangan dialog strategis, pertukaran informasi, mendorong stabilitas lewat kerjasama, melakukan tindakan yang mendorong saling percaya dan peningkatan keamanan, serta memperbaiki kontrol demokratis, reformasi militer dan latihan militer (Marcel, 2014: 161). Penjelasan ini semakin memperkuat urgensi peran diplomasi pertahanan sebagai instrumen penting dalam menggalang kerjasama dengan pihak lain untuk mencapai tujuan bersama. 


\section{Pembahasan}

\section{A. Diplomasi Pertahanan Indonesia dengan AS 2004-2009}

Tahun 2002 forum Indonesia-US Security Dialogue (IUSSD) pertama dilaksanakan di Indonesia yang menghasilkan sejumlah poin yaitu agar kedua negara bertumpu pada dialog untuk meningkatkan frekuensi komunikasi dan mendorong kerjasama melalui kunjungan pada tingkat menteri dan pejabat tinggi. Kemudian pada 2004, IUSSD ke 2 dilaksanakan di Amerika Serikat, kedua belah pihak sepakat bahwa forum ini penting dalam rangka menjalin komunikasi yang intensif bagi kedua institusi pertahanan. Pada pertemuan IUSSD kedua ini dibahas sejumlah isu yaitu perlu diadakannya Bilateral Defense Dialog (BDD) antara militer yaitu US Pacific Command dan Mabes TNI, Namru (Naval Medical Research Unit), soal pasal 98 statuta Roma, dan normalisasi hubungan militer kedua negara (Kemhan 2001). Terlihat dari pertemuan kedua ini ada keinginan melakukan normalisasi hubungan kerjasama pertahanan. Pada saat itu, Indonesia masih terdaftar dalam pelarangan pembelian senjata mematikan (lethal weapon) dalam pembatasan kerjasama militer yang dikeluarkan
Kongres AS kecuali dengan TNI AL pasca referendum Timor Timur pada 1999 (Congressional Record 2005). Sebagai akibat embargo tersebut banyak peralatan militer seperti suku cadang pesawat F-16 dan herkules yang tidak bisa dibeli Indonesia.Sehingga IUSSD adalah forum yang tepat untuk membahas normalisasi tersebut.

Pada Mei 2005, Presiden Susilo B. Yudhoyono melakukan kunjungan resmi ke AS dan melakukan pembicaraan dengan Presiden AS Geoge W. Bush. Dalam akhir pertemuan ini, kedua kepala negara menyatakan akan mempererat kerjasama di semua bidang, khususnya bidang keamanan Presiden Bush berkomitmen memulihkan kerjasama pertahanan. Dalam pernyataan resmi bersama menyatakan sebagai berikut (White House 2005);

"Presiden Bush dan Presiden Yudhoyono sepakat bahwa normalisasi hubungan militer antara RI dan AS adalah demi kepentingan bersama, serta berupaya untuk terus berkerja dalam mencapai tujuan tersebut.Kedua presiden menyambut secara baik atas partisipasi Indonesia dalam program IMET sebagai satu langkah tepat. 
Keduanya juga mengatakan berkeinginan bertemu kembali dalam aktivitas Dialog Strategis Keamanan Indonesia dan $A S$ di Jakarta pada 2005 dan mendorong upaya dialog bilateral antara militer kedua negara."

Pertemuan kedua kepala negara ini adalah momen bersejarah dalam pemulihan hubungan kerjasama politik dan keamanan terutama soal kerjasama militer.Selain itu, kedua negara sepakat untuk melanjutkan kerjasama di bidang penegakan hukum dan kontraterorisme, karena kedua negara memiliki kesamaan pandangan dalam melihat fenomena keamanan regional dan global yang harus diatasi melalui kerjasama antar negara.Kedua negara sepakat bekerjasama di berbagai bidang lainnya demi kepentingan bersama sebagai negara sahabat.

Pada pertemuan III IUSSD tahun 2005, masalah yang dibahas lebih beragam antara lain yaitu, situasi keamanan global dan regional, peran militer dalam penanggulangan bencana, upaya Indonesia melawan terorisme, manajemen sumber daya pertahanan, kerjasama International Military Education and Training (IMET), Foreign
Military Financing (FMF) dan Foreign Military Sales (FMS). Saat itu, delegasi Indonesia dipimpin oleh Menteri Pertahanan Juwono Sudarsono yang mengatakan bahwa pentingnya dialog agar saling memahami posisi, persepsi kebijakan antara kedua negara (Kemhan 2010). Sedangkan delegasi AS dipimpin oleh B.G. John Allen, Principal Director for Asia and Pacific Affairs, International Security Affairs, Department of Defense, AS dan didampingi pejabat dari Kemlu AS, US Pacific Command, dan Kedutaan Besar AS di Jakarta. Dalam sambutannya Duta Besar AS untuk Indonesia Lynn B. Pascoe mengatakan dialog ini adalah forum yang tepat untuk bekerjasama dalam periode kritis dalam hubungan militer kedua negara.

Akhirnya, November 2005 hubungan militer kedua negara kembali terjalin dengan dikeluarkan surat resmi dari Office of Defense Cooperation (ODC) dari Kedutaan Besar AS di Jakarta tentang Resumption of full military to military relations wih Indonesia. Menurut Kemhan keputusan ini diambil karena Indonesia dinilai berhasil dalam proses demokratisasi dan penegakan HAM (Kemhan 2010). Tetapi 
yang patut dilihat pula adalah kedua negara memiliki kepentingan yang sama terkait dengan perkembangan lingkungan strategis yaitu terjaminnya stabilitas politik dan keamanan di kawasan Asia Tenggara.

IUSSD ke IV dilaksanakan di Washington DC tahun 2006, di mana delegasi AS dipimpin Richard Lawless, Deputy Under Secretary of Defense, menyatakan pentingnya dialog antara pemerintah Indonesia dan AS sebagai wadah untuk menyampaikan pandangan tentang situasi keamanan di berbagai kawasan dan tantangannya serta mempererat hubungan kerjasama pertahanan (Kemhan: 2010). Sedangkan, Duta Besar RI Sudjanan Parnohadiningrat mengatakan perkembangan positif di dalam negeri merupakan prakondisi bagi peningkatan dialog agar kedua negara memetik manfaat dalam upaya bersama menciptakan keamanan global dan regional yang aman dan stabil. Beberapa hal dibahas pihak Indonesia, yaitu Assessment of US-Indonesia Relations, Indonesia's national security issues, update on defense sector reform dan USIndonesia Strategic Partnership. Delegasi Indonesia tidak memiliki permintaan spesifik namun menyatakan niat memanfaatkan program Defense Resources Management (DRM) dan National Guard State partnership. Dalam dialog ini, kedua negara menggarisbawahi lagi soal hasil pertemuan kedua kepala negara di tahun 2005 antara Presiden George W. Bush dan Susilo B. Yudhoyono yang menyimpulkan bahwa kedua negara memiliki kepentingan bersama untuk melakukan normalisasi kerjasama militer dan menyambut pemulihan program IMET bagi militer Indonesia (Kemhan: 2010).

Selanjutnya dalam upaya peningkatan kerjasama militer, pada 2006 Menteri Pertahanan AS Donald Rumsfeld berkunjung ke Jakarta untuk bertemu dengan Presiden Republik Indonesia Susilo B. Yudhoyono dan sejumlah menteri seperti Menteri Pertahanan Juwono Sudarsono dan Menteri Luar Negeri Hasan Wirayudha. Dalam pertemuan ini, SBY menyebutkan pentingnya normalisasi hubungan militer kedua negara sehingga kerjasama dapat dipermanenkan, serta Presiden SBY atas nama pemerintah RI mengucapkan terima kasih atas bantuan yang diberikan AS dalam penanggulangan bencana 
gempa dan tsunami di Aceh tahun 2004 dan gempa bumi Jawa Tengah tahun 2006. Sedangkan Rumsfeld menyatakan dirinya adalah salah satu pihak yang mendorong perubahan kebijakan terkait normalisasi tersebut termasuk dalam melobi Kongres AS (NYT: 2006). Selanjutnya, Menhan Juwono Sudarsono mengatakan kedua pihak antara lain membicarakan topik keamanan maritim di Selat Malaka dan keinginan Indonesia untuk membeli suku cadang pesawat F16.

Pada tahun 2007 dalam pertemuan IUSSD di Jakarta, pimpinan Delegasi Indonesia Mayjen.Dadi Susanto menyatakan pentingnya bertukar pandangan dan gagasan terbaik dalam merespons setiap tantangan di era globalisasi.Selanjutnya, DadiSusanto menyatakan pentingnya dialog untuk memperbaiki pemahaman, persepsi dan kebijakan masing-masing negara dalam isu-isu keamanan di tingkat regional dan internasional, sehingga dapat mengurangi kesalahpahaman diantara kedua negara. Demikian pula pimpinan delegasi AS menyatakan dialog yang diadakan kedua negara dapat memantapkan dan meningkatkan hubungan antara RI dan AS (Kemhan 2010). Dalam kesimpulan pertemuan IUSSD 2007 ini, ada beberapa program yang diusulkan AS salah satunya yaitu Global Peace Operation Initiative (GPOI) yakni AS memberikan bantuan technical assistance untuk peningkatan kapasitas militer Indonesia dalam operasi perdamaian dunia (Peace keeping operation). Dalam pertemuan ini, delegasi AS menyampaikan bahwa (Kemhan 2010):

\section{"Indonesia sebagai partner} strategik atau kunci dalam memerangi terorisme dikawasan ini. Kemajuan pesat Indonesia dalam memerangi terorisme menjadi catatan penting dan AS juga memberikanucapan selamat atas keberhasilan Kontingen Garuda di Lebanon, serta AS mengakui harus belajar banyak dari Indonesia..."

Salah satu kesepakatan yang dihasilkan forum ini yakni pencabutan embargo militer sudah memulihkan kembali program-program IMET sehingga dapat meningkatkan profesionalisme TNI di masa mendatang. Hasil kesepakatan dalam forum ini antara lain adalah kelanjutan program FMF (Foreign Military Financing), IMET, dan peningkatan pendidikan dan pelatihan. 
Bahkan dalam forum ini dibahas pula kerjasama militer bilateral yang direncanakan sebanyak 147 kegiatan selama tahun 2007 (Kemhan, 2010). Intinya kedua negara sangat berkeinginan melakukan kerjasama pertahanan karena adanya kepentingan strategis yang sama.

Tahun 2007, Panglima Angkatan Bersenjata AS Jenderal Peter Pace berkunjung ke Indonesia dan bertemu dengan Presiden RI Susilo B. Yudhoyono.Dalam pertemuan ini mereka membicarakan kerjasama militer pasca pencabutan embargo senjata. Selanjutnya pada bulan April 2007, Menteri Pertahanan Juwono Sudarsono berkunjung ke AS dan bertemu dengan Menlu AS Condoleeza Rice. Dalam pertemuan ini Juwono menyatakan perlunya peningkatan kerjasama militer terutama bantuan kapasitas kepada pasukan elit TNI AD yakni Kopassus. Hal ini direspon oleh Menlu AS bahwa AS siap membantu, tetapi kerjasama dengan Kopassus akan diupayakan secara bertahap untuk menghindari penolakan dari sejumlah pihak yang masih keberatan dengan kerjasama militer AS - Indonesia (Kemhan, 2010).

Kemudian pada 2008, dialog strategis antara RI dan AS dilaksanakan di AS.Dalam forum ini diharapkan dapat mengeksplorasi peluang kerjasama yang ditimbulkan oleh perubahan fenomena global dan regional dalam rangka semakin memperkuat strategic partnership antara Indonesia - AS dalam menghadapi tantangan keamanan bersama di kawasan. Sejumlah topik dibahas dalam forum yaitu soal Indonesia's Defense White Paper, FMS, FMF, IMET, MoU Framework of Defense Activities, dan lain lain. Dalam pembahasan tentang pelibatan TNI dalam kerjasama militer dengan AS, delegasi Indonesia meminta pihak mitra di AS memulihkan kerjasama dengan Kopassus dengan tidak terlalu mengeksploitasi isuisu di masa lalu. AS merespon hal yang terkait dengan Kopassus itu, pemerintah AS akan mempertimbangkan dengan matang karena peluang kerjasama ataupun tidak dengan Kopassus tetap melibatkan Kongres AS sebagai otoritas sipil (Kemhan 2010). Pada saat itu pimpinan delegasi AS menyatakan kepuasan atas perkembangan situasi politik di Indonesia dan khususnya reformasi TNI walaupun menyadari masih ada beberapa masalah yang belum selesai. 
Kunjungan resmi Presiden Indonesia Susilo B. Yudhoyono ke Amerika Serikat tahun 2008 menandakan bahwa hubungan kedua negara makin meningkat. Presiden Susilo B. Yudhoyono berkesempatan memberikan paparan dalam suatu diskusi di USINDO, dimana pejabat Departemen Luar Negeri AS John Negroponte mengatakan (USINDO, 2008):

"....Sejak memulihkan hubungan
militer pada tahun 2005, kami
telah meningkatkan kerjasama
dan pertukaran pada bantuan
bencana, perdamaian, dan
keamanan regional dan
maritim...."

Pernyataan Wakil Menlu AS John Negroponte mengindikasikan ada peningkatan kerjasama pertahanan antara kedua negara terutama di bidang penanggulangan bencana, keamanan maritim, maupun terkait persoalan regional lainnya.

Pada 2009, dialog strategis antara Indonesia dan AS yang dilaksanakan di Jakarta. Delegasi RI dan AS menyatakan forum ini amat penting bagi peningkatan hubungan pertahanan kedua negara seiring dengan semangat pembentukan Comprehenship Partnership yang sedang dipersiapkan bersama dan akan ditandatangani oleh pemimpin kedua negara. Pimpinan delegasi Indonesia menyatakan dialog inidiharapkan dapat meminimalisir kesalahpahaman yang mungkin terjadi antara kedua belah pihak. Kemudian, pimpinan delegasi AS Robert Scher,Deputy Assistant Secretary of Defense for South and Southeast Asia, Office of the Secretary of Defense,menyampaikan bahwa Indonesia mempunyai posisi yang amat penting dan berharga di mata Amerika maupun dunia pada saat ini (Kemhan, 2010). Kemudian, isu-isu yang dibahas dalam forum kali ini selain topik kerjasama militer antara kedua negara, yaitu soal perkembangan lingkungan strategis di Asia Pasifik termasuk juga isu-isu terkini di Asia Selatan.Sehingga kedua belah pihak dapat memahami posisi dan persepsi masing-masing terkait sejumlah isu yang berkembang saat itu.

Dari penjelasan di atas dapat diambil benang merah bahwa kedua negara terlihat mengedepankan diplomasi pertahanan dalam bentuk forum dialog, kunjungan antar pejabat tinggi dari Kementerian Pertahanan dan militer, kunjungan tingkat tinggi, dan lain-lain. Diplomasi melalui forum IUSSD adalah 
bagian dari peningkatan kepercayaan diantara kedua belah pihak agar dapat memahami posisi dan persepsi masing masing sekaligus ajang pembahasan normalisasi kerjasama pertahanan. Terlihat sekali bahwa upaya mengembangkan saling percaya dalam bentuk dialog dan negosiasi menjadi sangat penting dalam meningkatkan kerjasama pertahanan dan keamanan kedua negara. Kalau melihat tujuan dari diplomasi pertahanan seperti meningkatkan daya tawar, meningkatkan kontak, dan meningkatkan saling kepercayaan kedua pihak, maka bentuk dialog dan kunjungan antar pejabat tinggi berhasil meningkatkan kerjasama militer (Supriyatno, 2014: 176-178).Intinya kedua belah pihak memahami kerjasama adalah pilihan rasional dalam menghadapi ancaman keamanan yang dihadapi kedua negara, terutama yang berasal dari regional dan internasional.

\section{B. Pembelian Senjata AS dalam pembangunan Kapabilitas TNI}

Yang dimaksud dengan pembangunan kapabilitas militer adalah pembelian alat utama sistem senjata dan peralatan lain dalam memenuhi tujuan pertahanan. Dapat dikatakan pada era 2004-2009, hampir tidak banyak aktivitas pembelian senjata yang terjadi, dan bisa dikatakan hanya yakni pembelian suku cadang untuk pesawat, kapal frigat dan peralatan lainnya.

Selanjutnya pasca terpilih Presiden AS Barack Obama tahun 2008, sebenarnya embargo bukan masalah lagi karena dalam paparan di atas sudah terjadi normalisasi hubungan militer kedua negara.Pengamat militer Dr. Kusnanto Anggoro berpendapat, "Isu embargo senjata AS terhadap Indonesia yang selama ini menjadi barang 'dagangan' tak seharusnya dibahas lagi.Dalam pandangan Kusnanto, yang sesungguhnya terjadi, pemerintah memang tak mempunyai uang untuk membeli senjata dari Amerika Serikat dan bukan persoalan embargo" (Kompas, 27/10/2008).Pada masa pemerintahan Presiden SBY periode I, memang tidak banyak pembelian senjata yang dilakukan Indonesia, karena Indonesia masih berupaya memperbaiki ekonomi domestik pasca krisis moneter regional 1997-1998.

Namun, pada periode tahun 20062008 pemerintah AS memberikan bantuan program Integrated Maritime Surveillance System (IMSS) yaitu hibah senilai US \$ 57 Juta. IMSS adalah suatu 
sistem pengawas dan pendeteksi untuk wilayah laut teritorial dan perairan internasional yang terdiri dari radar, komunikasi, peralatan lainnya yang terintegrasi antara perangkat di darat dengan di laut (Department of State, 2004). Sistem IMSS sangat membantu Indonesia dalam menanggulangi ancaman perompakan dan memantau pergerakan kapal yang ada di Selat Malaka, Selat Sulawesi dan Selat Makassar.

Untuk melihat lebih jauh seberapa banyak suku cadang senjata dan peralatan militer yang dipasok AS ke Indonesia, dapat dilihat Kotak 1. Sebagian besar transfer senjata berupa peralatan pendukung militer seperti radar, mesin turbo, mesin diesel untuk kapal corvettelfrigate, dan hanya ada satu pengiriman pesawat F-5E tiger yang diembargo tahun 1999. Data ini menunjukkan bahwa Indonesia selama 2003-2009 belum membeli alutsista secara signifikan dari AS agar bisa meningkatkan kapabilitas militernya.Seperti penjelasan sebelumnya Indonesia masih dalam tahap reformasi politik dan ekonomi sehingga lebih fokus dalam menghadapi persoalan internal.Pembelian suku cadang tersebut lebih pada prioritas kebutuhan pasca embargo dan juga dalam soal menghadapi ancaman regional khususnya keamanan maritim di Selat Malaka.

Di lain pihak, pasca pemulihan kerjasama militer tahun 2005, Indonesia harus menandatangani perjanjian 505 yang merupakan jaminan pemerintah Indonesia terhadap semua alutsita/peralatan yang dibeli dari AS. Perjanjian 505 ini berisi, pertama, Indonesia tidak akan melakukan perpindahtangan kepada pihak setiap bantuan militer peralatan militer (excess defense article) yang dihibahkan; kedua, memberlakukan tingkat kerahasiaan terhadap peralatan militer yang dihibahkan sesuai dengan tingkat kerahasiaan yang diberlakukan AS; ketiga, kesediaan Indonesia untuk mengembalikan defense article yang pernah dihibahkan, apabila telah rusak atau tidak digunakan lagi (Kemhan, 2010). Selain itu ada juga perjanjian CISMOA (Communication Interoperability and Security \& Memorandum of Agreement) yang harus ditandatangani pejabat kedua negara terkait keamanan komunikasi dari peralatan milik AS yang digunakan Indonesia. 


\begin{tabular}{|l|l|}
\hline MANDALA & Vol.1 No.1 \\
Jurnal Ilmu Hubungan Internasional & Januari- Juni \\
2017
\end{tabular}

Tabel 1.1 Transfer Senjata Konvensional Utama dari Amerika Serikat ke Indonesia tahun 2003-2009

\begin{tabular}{|c|c|c|c|c|c|c|c|}
\hline $\begin{array}{l}\text { Penerima/ } \\
\text { supplier }(\mathrm{S}) \\
\text { atau licenser }(\mathrm{L})\end{array}$ & $\begin{array}{l}\text { Jumlah } \\
\text { order }\end{array}$ & $\begin{array}{l}\text { Nama } \\
\text { Senjata }\end{array}$ & $\begin{array}{l}\text { Deskripsi } \\
\text { senjata }\end{array}$ & $\begin{array}{l}\text { Tahun } \\
\text { order/lisensi }\end{array}$ & $\begin{array}{l}\text { Tahun } \\
\text { pengiriman }\end{array}$ & $\begin{array}{l}\text { Jumlah } \\
\text { dikirim/ } \\
\text { Diproduksi }\end{array}$ & Keterangan \\
\hline \multirow{3}{*}{$\begin{array}{l}\mathrm{R}=\mathrm{INA} \\
\mathrm{S} / \mathrm{L}=\text { Amerika Serikat }\end{array}$} & \multirow{2}{*}{76} & APG-66 & $\begin{array}{l}\text { Radar } \\
\text { tempur }\end{array}$ & 1996 & $1999-2007$ & (16) & $\begin{array}{l}\text { Untuk } 16 \text { pesawat tempur Hawk- } \\
200 \text { dari Inggris; status dari } 6 \\
\text { item terakhir tidak pasti setelah } \\
\text { embargo senjata AS terhadap } \\
\text { Indonesia pada 1999-2006 }\end{array}$ \\
\hline & & TPE-331 & Turboprop & 1996 & $2005-2007$ & 12 & $\begin{array}{l}\text { Untuk } 6 \text { pesawat C-212 MP dari } \\
\text { Spanyol }\end{array}$ \\
\hline & & Caterpillar- & Mesin & 2000 & $2002-2005$ & 8 & Untuk modernisasi 4 parchim \\
\hline
\end{tabular}

Prodi Ilmu Hubungan Internasional FISIP UPN"Veteran" Jakarta 


\begin{tabular}{|l|l|}
\hline \hline MANDALA & Vol.1 No.1 \\
Jurnal Ilmu Hubungan Internasional & Januari- Juni \\
2017
\end{tabular}

\begin{tabular}{|l|l|l|l|l|l|c|l|}
\hline & & 3516 & diesel & & & & corvette (Pattimura) \\
\hline & $\begin{array}{l}\text { Caterpillar- } \\
3612\end{array}$ & $\begin{array}{l}\text { Mesin } \\
\text { diesel }\end{array}$ & 2002 & 2003 & 2 & $\begin{array}{l}\text { Untuk modernisasi } 1 \quad \text { frigate } \\
\text { Yani (Van Speijk) }\end{array}$ \\
\hline & $\begin{array}{l}\text { Caterpllar- } \\
3616\end{array}$ & $\begin{array}{l}\text { Mesin } \\
\text { diesel }\end{array}$ & 2006 & $2007-2008$ & 8 & $\begin{array}{l}\text { Untuk modernisasi } 4 \text { frigate } \\
\text { Yani (Van Speijk) }\end{array}$ \\
\hline
\end{tabular}

Sumber: SIPRI Arms Transfers Database

Informasi diakses: 09 Agustus 2016: http://www.sipri.org/contents/armstrad/at_data.html.

Catatan: Kolom 'Jumlah dikirim/diproduksi' dan 'Tahun pengiriman' merujuk pada semua pengiriman sejak permulaan kontrak. Kesepakatan di mana penerima terlibat dalam produksi sistem persenjataan di-listing secara terpisah. Kolom 'Keterangan' menjelaskan informasi tentang nilai dari kesepakatan yang dilaporkan secara publik.Informasi tentang sumber-sumber dan metode-metode yang digunakan dalam pengumpulan data, dan penjelasan atas beberapa kebiasaan, singkatan dan akronim bisa dilihat di URL $<$ http://www.sipri.org/contents/armstrad/at_data.html>.SIPRI Arms Transfers Database selalu di-update seiring dengan informasi baru yang didapatkan.

Prodi Ilmu Hubungan Internasional FISIP UPN"Veteran" Jakarta 


\section{Diplomasi Pertahanan Indonesia dengan AS 2009-2014}

Salah satu momen penting dalam peningkatan hubungan RI dan AS di bidang pertahanan adalah kunjungan Menteri Pertahanan AS Robert Gates ke Indonesia, pada Juli 2010.Di Jakarta, Robert Gates bertemu Presiden Susilo B. Yudhoyono dan Menteri Pertahanan RI Purnomo Yusgiantoro. Terkait kunjungannya kali ini,Gates menyatakan (Gates 2010),

"Pada malam kunjungan kedua saya sebagai Menteri Pertahanan Amerika Serikat, saya memiliki kesempatan untuk merefleksikan betapa hubungan AS-Indonesia telah semakin erat sejak itu, dan berapa banyak lagi yang bisa kita lakukan secara bersama atas nama keamanan dan kemakmuran bagi kedua negara kita, maupun untuk wilayah Asia Pasifik dan dunia."

Secara faktual kerjasama pertahanan kedua negara seperti disebutkan Gates bukan hanya untuk kepentingan negaranya, namun lebih luas yakni terciptanya stabilitas dan keamanan regional, maupun global. Memang kerjasama bilateral ini terfokus pada isu-isu seperti keamanan maritim, penanganan bencana, ancaman lingkungan dan lainnya. Sehingga, hubungan kerjasama ini bisa meningkatkan saling percaya di berbagai tingkatan institusi militer, serta hubungan profesional akan mudah terjalin antara kedua militer. Dengan demikian, kedua negara dapat mengatasi berbagai tantangan dan ancaman keamanan yang makin kompleks melalui kerjasama yang erat.

Tahun 2010 adalah pertama kalinya Presiden AS Barack Obama melakukan kunjungan resmi ke Indonesia setelah terpilih menjadi presiden pada 2008.Pada November 2010, Presiden Obama dan Presiden Susilo B. Yudhoyono melakukan penandatangan perjanjian berjudul US-Indonesia Comprehensive Partnership, yang berisi kerjasama bilateral antara RI dan AS di berbagai bidang yaitu politik, keamanan, pendidikan, energi, sosial dan lainlain. Saat itu, Duta Besar Indonesia 
untuk AS Dino Patti

Djalalmengatakan bahwa kemitraan kedua negara ini menjadi landasan dasar bagi kesinambungan kerjasama bilateral di masa mendatang (Asia Society, 2010).Ini menandakan bahwa hubungan kedua negara sudah makin erat dan saling memahami bahwa dengan bekerjasama,makakedua negara dapat mengatasi berbagai persoalan secara lebih baik.

Untuk memahami lebih jauh tentang kerjasama keamanan di antara kedua negara itu, maka salah satu poin dalam perjanjian ini menyatakan (Department of State, 2010);

"To strengthen bilateral defense and security cooperation through dialogue and capacity building as appropriate in areas such as security sector reform, training, education, personnel exchanges, intelligence exchange, peacekeeping operations, maritime security, nuclear safety and security, humanitarian assistance/disaster relief operations, and military equipment; to work together under the recently signed framework

arrangement

between the Government of the

Republic of Indonesia and the

Government of the United

States of America on

Cooperative Activities in the

Field of Defense."

Hal ini makin menguatkan bahwa kerjasama keduanya makin intens dan meningkat mengingat posisi kedua negara sebagai negara besar dan memiliki kepentingan strategis yang sama terutama untuk menjaga stabilitas politik dan keamanan di kawasan Asia Pasifik (Armed Force Press Service, 2010. Sehingga Indonesia secara politik dan militer harus menjadi mitra terdekat bagi AS yang memiliki kepentingan terhadap stabilitas di Lautan Hindia, Selat Malaka, dan kawasan Pasifik Barat. Jadi poin ini menunjukan bahwa Indonesia dan AS akan terus melakukan dialog dalam rangka memperkuat kerjasama untuk peningkatan kapasitas (capacity building) militer dan aparat keamanan lainnya.

Dalam mempererat hubungan antara kedua negara, maka kunjungan pejabat militer AS dan Indonesia terus dilakukan.Seperti yang dilakukan 
Panglima Armada Pasifik AS

Laksamana M. Patrick, ketika

melakukan pertemuan dengan

Panglima TNI Laksamana Agus

Suhartono, pada Januari 2011. Dalam

keterangannya tentang kunjungan

Panglima Armada Pasifik AS ini,

Kapuspen TNI Laksamana Muda

Iskandar Sitompul menyatakan bahwa

fokus pembicaraan antara kedua

pejabat militer yakni seputar evaluasi

kerja sama kedua negara terutama di bidang militer dan pertahanan yang telah berjalan baik. Dibicarakan pula upaya peningkatan yang dapat dilakukan kedua pihak di masa mendatang, seiring dengan perkembangan lingkungan strategis kawasan (Republika, 17/1/ 2011). Kunjungan ini sangat penting bagi kedua negara bahwa Indonesia memiliki peran strategis dalam stabilitas kawasan regional dan tentunya Indonesia bisa menyampaikan keinginan untuk bekerja sama lebih lanjut dengan militer AS.

Dalam pertemuan IUSSD IX di Indonesia tahun 2011 yang dihadiri Dubes RI untuk AS Dino Patti Djalal dan Dubes AS untuk Indonesia Scot A. Marciel. Delegasi Indonesia dipimpin Direktur Jenderal Stategi Pertahanan Mayor Jenderal Puguh Santoso mengatakan setelah penandatanganan

US-Indonesia

Comprehensive

Partnershiptahun sebelumnya, telah dibentuk Working Group on Security (WGS) untuk membicarakan hal hal spesifik di bidang keamanan. Puguh Santoso selanjutnya mengatakan dialog IUSSD ini dapat menciptakan kemajuan signifikan yang mendorong pemahaman lebih baik dan kerjasama yang lebih luas di bidang pertahanan antara kedua negara (Kemhan 2012). Sedangkan Robert Scher sebagai pimpinan delegasi AS mengatakan pentingnya kerjasama pertahanan antara Indonesia dan Amerika Serikat sebagai bagian dari hubungan yang kuat secara keseluruhan. Sejumlah isu diangkat dalam dialog ini yakni selain isu-isu keamanan regional dan global, tentunya kerjasama bilateral menjadi bahasan terutama peningkatan kerjasama keamanan maritim atau maritime security (MARSEC), operasi perdamaian $(P K O), \quad$ bantuan kemanusiaan dan mitigasi bencana $(H A D R)$ dan lain- lain.

Sementara dalam sambutannya, Duta Besar RI Dino 
Patti Djalal mengatakan hubungan antara RI dan AS saat ini adalah terbaik terutama setelah penandatanganan perjanjian USIndonesia Comprehensive Partnership itu. Dino mengatakan kerjasama bilateral sektor keamanan sudah beradaptasi dengan sangat baik dibandingkan sektor lain, khususnya dalam kecepatan dan substansi kerjasama (Kemhan, 2012). Sehingga kerjasama ini perlu mengarah pada tingkat yang lebih tinggi dan bagaimana tantangan baru bisa dihadapi secara bersama.Kehadiran kedua Duta Besar ini menunjukkan bahwa kerjasama pertahanan mendapat perhatian yang serius bagi kedua negara karena kedua negara memiliki kesamaan pandangan terkait isu-isu regional dan global.

Tahun 2012, pertemuan IUSSD X dilakukan di AS bersamaan dengan pertemuan Joint Commisison Meeting (JCM) antara Menlu kedua negara yaitu Hilary Clinton dan Marty Natalegawa. Dalam pertemuan IUSSD setidaknya ada sepuluh isu yang menjadi bahasan yaitu US rebalance to Asia Pacific, Indonesia's Dynamic Equilibrium, kerjasama militer AS-RI, progress of ADMM/ADMM+ meeting, keamanan perbatasan, kapabilitas pertahanan, pasukan perdamaian, penanggulangan bencana, cyber space dan lainnya (Laporan Kemhan: 2012). Delegasi AS Peter Lavoy mengatakan AS memiliki kesamaan pandangan, nilai-nilai dan visi dengan RI dalam arah kebijakannya di dunia khususnya kawasan Asia Pasifik.Selanjutnya dia mengatakan dalam hubungan pertahanan bilateral AS dengan mitramitranya di kawasan ini menempatkan Indonesia sebagai salah satu negara prioritas.Hasil dari pertemuan IUSSD ini yakni AS sangat menghargai kepemimpinan Indonesia di Asia Tenggara (ASEAN) terutama dalam isu Laut Cina Selatan dan lain lain. Selain itu penyerahan pesawat F-16 agar dapat dipercepat, serta AS akan membantu Indonesia dalam program GPOI melalui pemberian hibah sebesar 8 juta dolar AS untuk pusat penjaga perdamaian (peacekeeping center)di Sentul (Sukadis: 2013).

Sedangkan JCM khususnya Working Group on Security (WGS) membahas delapan topik yaitu, dialog rencana pertahanan, percepatan penyerahan F-16, program FMS/FMF/IMET dan bantuan 
Integrated Maritime Surveillance

System (Department of State, 2011), bantuan kemanusiaan (HADR), bantuan untuk IPSC (Indonesian Peacekeeping and Security Center), kerjasama maritim dan cyber defense. Dalam dialog JCM ini kedua negara mengakui kesepahaman bahwa hubungan pertahanan mengalami peningkatan dan kualitas, serta penting untuk lebih ditingkatkan pada masa datang (Kemhan, 2012). Lebih lanjut kedua Menlu menyatakan kerjasama pertahanan RI dan AS dapat dipertahankan dan bahkan ditingkatkan serta saling menguntungkan bagi kepentingan kedua belah pihak.Kedua Menlu menyatakan menerima hasil kertas kerja WGS dan sepakat memajukan kerjasama bilateral bidang pertahanan khususnya isu HADR, peacekeeping, dan dialog keamanan dalam mendukung perdamaian di tingkat regional dan global.

$$
\text { Pada tahun 2013, dialog }
$$
IUSSD ke-XI dilaksanakan di Jakarta. Dalam pertemuan ini dihasilkan beberapa butir antara lain, pihak AS memberikan penghargaan pada kemajuan demokrasi dan hukum di Indonesia, serta peran aktif Indonesia di Asia Tenggara dalam berbagai isu keamanan regional (Kemhan, 2013). Selain itu AS menyadari bahwa sejumlah negara ASEAN bersama Jepang, India, Korsel dan RRC sedang melakukan modernisasi militer secara sangat intens.Pihak AS menjelaskan kebijakan rebalancing ke kawasan Asia Pasifik sebagai fokus utama, mengingat perkembangan situasi di kawasan ini sangat berpengaruh terhadap stabilitas keamanan dunia.Kebijakan keamanan AS ditujukan agar dapat meningkatkan kerjasama pertahanan dengan negara negara di kawasan ini.Pihak AS berharap Indonesia bisa membantu menjelaskan pada negara-negara di kawasan Asia Tenggara mengenai sikap dan upaya AS terhadap kawasan ini (Kemhan 2013). Dalam pertemuan ini AS menawarkan program capacity building yaitu Defense Language Institute (DLI), yakni berupa proyek pengembangan bahasa Inggris senilai 1,2 juta dolar AS yang akan disalurkan melalui Office of Defense Cooperation (ODC) Kedubes AS.

Terjalinnya kerjasama pertahanan AS dan Indonesia secara baik menjadi bukti bahwa hubungan kedua negara semakin erat dan 
meningkat, walaupun pemerintah Indonesia sudah berganti dari Presiden Susilo B. Yudhoyono ke Joko Widodo. Hal ini dinyatakan oleh pimpinan delegasi AS dalam pertemuan IUSSD ke XII, pada Desember 2014, yaitu forum dialog ini sebagai bentuk momentum kerjasama pertahanan yang perlu dipertahanankan (Kemhan, 2015). Pemerintah AS menyatakan tetap berkomitmen untuk melanjutkan dukungan bagi program IMET, FMF, DIRI yang selama ini telah berjalan. Sedangkan delegasi Indonesia menyatakan bahwa forum IUSDD ini diharapkan memberikan peluang untuk memperluas dan merealisasikan program-program kerjasama pertahanan kedua negara (Kemhan, 2015).

Adanya peningkatan kerjasama baik secara kualitas dan kuantitas dikuatkan oleh pernyataan mantan Direktur Kerjasama Internasional (Dirkersin 2011-2014), Brigadir Jenderal Jan Pieter Ate mengatakan bahwa IUSDD memiliki dampak positif bagi kerjasama pertahanan kedua negara (Jan Ate, 2016).Peningkatan kerjasama ini sangat erat dikaitkan dengan perkembangan lingkungan strategis dan juga perkembangan Indonesia pasca krisis ekonomi.

\section{Pendidikan dan pelatihan}

Dilihat aktivitas diplomasi Indonesia kepada AS dan sebaliknya melalui sejumlah tawaran kerjasama AS pada Indonesia selama kurun waktu 2009-2014, ternyata kerjasama di bidang pendidikan dan pelatihan masih mendominasi hubungan kerjasama pertahanan.Kegiatan pendidikan dan pelatihan inisangat berkaitan dengan alutsista TNI yang sebagian besar berasal dari AS.Bahkan, data tahun 2004 terlihat bahwa produsen senjata AS menyumbang sebesar $34 \%$ alutsista dan peralatan TNI, artinya AS adalah nomor satu dibanding negara lainnya (Widjajanto dan Keliat, 2008: 21-22). Pendidikan dan pelatihan bagi personel militer Indonesiaagar mereka dapat mengoperasikan alutsista dan peralatan militer yang berasal dari AS. Selanjutnya, Kolonel Inf. Rodon Pedrason Kepala Prodi Diplomasi Pertahanan Unhan, mengatakan pendidikan dan pelatihan di luar negeri yang diikuti personel TNI sebagian besar dilakukan oleh institusi pendidikan militer AS, karena AS 
adalah penyumbang alutsista terbesar ke Indonesia dengan kata lain Indonesia adalah pengguna persenjataan standar NATO atau AS [Wawancara Rodon Pedrason, 5 Februari 2016]. Sehingga, sangat logis kalau Indonesia mengirim para personel ke AS sebagai pusat pendidikan terbaik dan sesuai dengan alutsista yang dimiliki.

\section{Program International Military}

and Education Training (IMET), Combating Terrorism Fellowship Program (CTFP), dan Foreign Military Financing (FMF) masih menjadi primadona dalam kerjasama pertahanan Indonesia dan AS, yaitu terlihat dalam Tabel 2 dibawah. Program IMET adalah program pengiriman personel militer dan sipil dalam pendidikan sekolah staf dan komando, sekolah angkatan perang, kursus lanjutan perwira, defense college, dan kursus singkat lainnya. Tujuan dari pelaksanaan IMET ini didesain untuk peningkatan profesionalisme militer, memperbaiki interoperabilitas antar angkatan, mendorong reformasi institusi pertahanan dan memberikan pengetahuan tentang hubungan sipilmiliter, penyusunan anggaran militer, dan lainnya. CTFP adalah program pelatihan kontraterorisme bagi aparat intelijen dan militer agar dapat memahami bentuk dan ancaman teror serta bagaimana melakukan deteksi terhadap kelompok teror. 
Tabel 2. Peserta Pendidikan dan Pelatihan di Amerika Serikat 2010-2014

\begin{tabular}{|l|c|c|c|c|c|}
\hline \multicolumn{1}{|c|}{ Tahun } & $\mathbf{2 0 1 0}$ & $\mathbf{2 0 1 1}$ & $\mathbf{2 0 1 2}$ & $\mathbf{2 0 1 3}$ & $\mathbf{2 0 1 4}$ \\
\hline Program & & & & & \\
\hline CTFP & 3 & 2 & 3 & 2 & 2 \\
\hline DHS/USCG & 67 & 22 & 66 & 54 & 26 \\
\hline FMF & - & 4 & 80 & 6 & 29 \\
\hline FMS & 45 & 40 & 57 & 57 & 101 \\
\hline GPOI/PKO & 29 & 63 & 126 & 43 & 196 \\
\hline IMET & 57 & 73 & 76 & 49 & 71 \\
\hline Misc.DOD/DOS /Non & 354 & 1 & - & - & 800 \\
SA, UC, JCET & & & & & \\
\hline Regional center & 31 & 59 & 59 & 18 & 45 \\
\hline Section 1206 & - & 148 & - & - & - \\
\hline Exchange & - & - & 4 & - & - \\
\hline \multicolumn{1}{|c|}{ Total } & $\mathbf{7 0 5}$ & $\mathbf{5 2 3}$ & $\mathbf{5 1 9}$ & $\mathbf{2 6 9}$ & $\mathbf{1 2 9 7}$ \\
\hline
\end{tabular}

Diambil dari laporan Foreign Military Training, Report to US Congress, Joint Report by DoD and DoS, USA, from 2009-2014. 
Tabel 2 diatas menggambarkan bahwa kuantitas kerjasama pertahanan makin meningkat kalau dibandingkan dari tahun 2010 sebanyak 705 peserta hingga 2014 (1.297), kecuali pada 2013 (269) terjadi penurunan drastis. Sejak tahun 2011 hingga 2013 jumlah peserta turun dari 523 menjadi 269 atau terjadi penurunan dibandingkan partisipasi tahun 2009 sebesar 819

peserta. Memang data dalam tabel diatas tidak menjelaskan kenapa terjadi naik turun, namun secara umum dapat disimpulkan terjadi peningkatan kegiatan dari aspek kualitatif dan kuantitatif berdasarkan hasil wawancara dengan berbagai pihak. Yang menarik penurunan peserta yang drastis pada 2013 mungkin terjadi karena ada kebuntuan dalam pembicaraan pemangkasan anggaran pemerintah federal AS (shutdown) yang dipimpin Presiden Barack Obama dengan Kongres AS yang dikuasai Partai Republik. Sementara itu, pada tahun 2014 terjadi lonjakan peserta sebanyak 1.297 personel yang mungkin akibat dari ekses shutdown pada tahun sebelumnya, artinya peserta yang mestinya berangkat tahun 2013 sangat mungkin berangkat pada 2014.

\section{Kesimpulan}

Berdasarkan analisis diplomasi pertahanan selama 10 tahun masa pemerintahan Presiden SBY, ada peningkatan kerjasama pertahanan Indonesia dengan AS baik secara kuantitas maupunkualitas (Hasil wawancara, 2015-2016). Kedua negara menyadari bahwa kerjasama pertahanan tidak bisa terelakkan karena situasi lingkungan strategis yang tidak menentu dankesamaan kepentingan strategis.

$$
\text { Perkembangan lingkungan }
$$
strategis terutamaberasal dari serangan teroris di AS, Indonesia, serta sejumlah negara semenjaktahun 2000an. Indonesia sendiri mengalami serangan dari kelompok Jamaah Islamiyah yang berbasis di Asia Tenggara. Ancaman terorisme menjadi isu kepentingan bersama kedua negara dalam melindungi keselamatan rakyat dan kedaulatan bangsa.

Selain itu, isu keamanan maritim, bencana alam, kontra terorisme dan operasi stabilitas atau misi damai(peace keeping operation) juga menjadi fokus kerja sama pertahanan kedua negara. Hal ini mencuat dalam laporan Deplu dan 
Dephan AS ke Kongres yang menyatakan bahwa kerjasama pertahanan dengan Indonesia dinilai sangat penting. Pasalnya, AS memandang masa depan politik dan ekonomi Indonesia memiliki implikasi langsung pada kepentingan strategis ASyaitu mengatasi terorisme, menjaga stabilitas kawasan Asia Tenggara, menjaga perkembangan demokasi dan HAM serta peluang bagi pasar ekspor dan investasi AS (Foreign Military Training Report, 2010.

Bagi Indonesia, kerjasama pertahanan ini sangat dibutuhkan guna meningkatkan kapabilitas pertahanan sesuai dengan program MEF yang dicanangkan sejak pemerintahan SBY. MEF adalah program untuk membangun postur pertahanan Indonesia yang diharapkan bisa rampung pada tahun 2029. Ketikamelihat dinamika kerjasama pertahanan antara Indonesia dengan AS, untuk memenuhi target postur pertahanan ini nampaknya agak sulit tercapai jika hanya mengandalkan AS. Alasannya saat ini AS bukan satusatunya sumber alutsista bagi Indonesia. Selain itu, alutsista buatan AS terbilang cukup mahal. Meskipun demikian, jumlah alutsista TNI yang berasal dari AS memang paling banyak dibandingkan keseluruhan negara eksportir senjata lainnya.

Kesimpulan yang diambil untuk menjawab pertanyaan penelitian ini tentang diplomasi pertahanan Indonesia dalam kerjasama pertahanan kedua negara, yaitu.Pertama, forum dialog IUSSD, maupun kunjungan pejabat tinggi dan pertukaran staf militer adalah sarana yang efektif dalam pelaksanaan diplomasi pertahanan karena membicarakan isuisu strategis bagi kerjasama kedua negara. Materi yang dibicarakan dalam forum dialog IUSSD sangat terbuka dan transparan. Hampir semua masalah baik kerjasama bilateral ataupun perkembangan situasi regional dan internasional dibicarakan secara terbuka, informal dan substantif. Artinya, kedua negara memahami posisi dan persepsimasingmasing dalam melihat isu-isu strategis. Hal ini mempercepat upaya membangun saling percaya $(C B M)$ untuk mencapai tujuan bersama.

Kedua negara dalam melihat isu keamanan dan strategis memiliki kesamaan pandangan terutama soal isukontra terorisme, stabilitas kawasan, konflik internasional, 
bencana alam, dan keamanan maritim. Kedua negara memiliki peluangkerjasama yang bagus dalam isu-isu tersebut. Alhasil, kegiatan diplomasi ini sesuai denganapa yang disebut Cottey dan Forster bahwa hal yang substantif dalam diplomasi pertahanan adalah terjadinya pertemuan reguler untuk membicarakan isu umum dan kerjasama spesifik (Supriyatno, 2014:188). Adapun, konsep diplomasi pertahanan Mihal Marcel menitikberatkan kerjasama antar negara di bidang militer dan keamanan secara global, sehingga kegiatan diplomasi pertahanan yang dilakukan Indonesia bisa memenuhi tujuan nasionalnya yaitu peningkatan stabilitas dan keamanan nasional dan regional.

Kedua, faktor kepemimpinan Presiden SBY sangat menentukan dalam mempererat hubungan kerjasama pertahanan kedua negara. Presiden SBY mempunyai latar belakang militer sehingga sangat paham apa yang harus dilakukan[wawancara, 2016]. Adapun, SBY memiliki kebijakan luar negeri "thousand friends, zero enemy" yang cenderung ingin bersahabat dengan semua negara. Salah satu hal penting yang dicapai pada masa pemerintahan SBY ialah penandatanganan kesepakatan Framework Arrangement on Cooperative Activities in the field of Defense between Indonesia and U.S Department of Defense dan USIndonesia Comprehensive Partnership tahun 2010. Kesepakatan tersebut adalah bentuk kemitraan bilateral paling tinggi dalam kerjasama pertahanan dan keamanan dan kerjasama di bidang lainnya. Bahkan, di tingkat pejabat tinggi pertahanan terjadi beberapa kali interaksi dalam rangka saling mengunjungi (high official visit). Semua itu menunjukkan kehangatan hubungan di antara kedua negara.

Ketiga, melihat intensitas, bentuk dan kualitas kerjasama pertahanan antara Indonesia dan AS maka periode kedua (II) pemerintahan SBY bisa disebut sebagai masa terbaik karena kerjasama pertahanan meningkat sangat pesat. Sesuai dalam pembahasan analisis dapat dinyatakan bidang pendidikan dan pelatihan (diklat) merupakan porsi terbesar dalam kerjasama pertahanan. Namun, kesepakatan pembelian alutsista dan kerjasama industri pertahanan belum 
banyak dilakukan. Pada saat itu belum ada upaya untuk melakukan pembelian alutsista diluar skema FMS dan FMF. Alasannya adalah karena tidak adanya kebijakan yang sustainable dan jelasdari Indonesia terkait pembelian alutsista dari AS. Selain itu, skemaoffsetbelum dilakukan dalam pembelian dengan mekanisme FMS karenatergantung dari komitmen pemerintah Indonesia. Namun, kerjasama industri pertahanan dalam hal offsetini bisa dilakukan karena Indonesia sudah memiliki pijakan hukum yakni UU No. 16 tahun 2012 tentang industri pertahanan.

$$
\text { Keempat, berdasarkan }
$$
analisisdapat disimpulkan bahwa jumlahpeserta diklat yang berasal dari militer lebih besar dibandingkan peserta dari sipil. Hal ini berakibat pada masih rendahnya kompetensi pegawai negeri sipil (PNS) di lingkungan Kemhan sehingga transformasi dan reformasi pertahanan belum bergerak maju seperti yang diharapkan banyak pihak. Artinya, perlu ada kebijakan dari kedua belah pihak yakni AS dan Indonesia untuk lebih berfokuspadapeningkatan kapasitas bagi kalangan sipil baik dari PNS, akademisi maupun lembaga penelitian. Dengan adanya sumber daya yang mumpuni dibidang pertahanan maka diharapkan dapat berkontribusi langsung pada hubungan sipil-militer yang ideal serta adanya transparansi dalam penyusunan kebijakan dan anggaran.

\section{DAFTAR PUSTAKA}

\section{Buku dan makalah}

Acharya, A.(2001), Constructing a Security Community in South East Asia: ASEAN and the Problem of Regional Order, London: Routledge.

Anwar, S. (Mayjen. purn), Meningkatkan Kapasitas dan Peran diplomat Pertahanan untuk membangun Pertahanan yang Tangguh; Jurnal Pertahanan, Mei 2012, Volume 2, No. 2: UNHAN.

Anwar, DF, (2005), Indonesia at Large, Democratization, Foreign Policy, Jakarta: The Habibie Center

Art, R. and Robert Jervis, eds. (2005), International Politics: Enduring Concept and Contemporary Issue, US: Pearson. 
Aspinall, E.,Mietzner, $\mathrm{M}$ and Tomsa,

D. eds. (2015), the Yudhoyono

Presidency: Indonesia Decade

of Stability and Stagnation,

Singapore:ISEAS,

Bisley, N. (2009), Building Asia's

Security, London:IISS and

Routledge.

Berridge,

GF.

(2005),

Diplomacy:Theory

and

Practice, NY (USA): Palgrave

McMillan,

Capie, D. and Taylor, B. (2010), The

Shangri-La Dialogue and the

Institutionalization of Defense

Diplomacy in Asia, The Pacific

Review, Vol. 23, No. 3, July 2010 .

Cottey, A. and Forster, A.(2004),

Reshaping Defense Diplomacy

: New Role for military

Cooperation and Assistance,

NY and London, (Adelphi

Series) Routledge

Conboy, K. (2008), Intelijen II:

Medan tempur Kedua, Jakarta:

Pustaka Prima.

Denmark, A. (2010), Crafting a

Strategic Vision: a New Era of

US and Indonesia

Relations(paper), Washington

DC:CNAS
Hills, A. (2000), Defense Diplomacy and Security Sector Reform, Contemporary Security Policy, 21:1, 46-67, DOI.

Junius, S.(2012), Politik Luar Negeri Indonesia Masa Presiden Susilo Bambang Yudhoyono terhadap ASEAN2004-2009, tesis, Jakarta: Universitas Paramadina

Kardi, K. Marsekal Muda (purn.),(2009), Permasalahan Pengadaan dan Perawatan Alutsista; makalah seminar, 7 Oktober 2009, Jakarta: LESPERSSI

Marcel, M. (2014), Promoting Security through Public Diplomacy, Military Art and Science, Revista Academei Fortelor Terestre No.2 (74): Rumania.

McAslan, H. (2004), Contemporary US Foreign Policy towards Indonesia (Thesis for Master degree in military science), Ft. Leavenworth, Kansas: US Army CGSC,

Morgenthau, H.J. (2006), Politics Among Nations, 7th edition, NY, USA: McGraw Hill. 
Muchtar, K. (1989),Diplomasi Ujung tombak Perjuangan RIM. Roem,Jakarta : Gramedia.

Nye Jr., J. (2011), The Future of Power, NY: Public Affairs,

Negroponte, J. (2008),Deputy Secretary of State Remarks at USINDO, Washington DC: USINDO.

Karim, S. (2014), Membangun Kemandirian Industri

Pertahanan Indonesia, Jakarta:

KPG Gramedia,

Obrien, A. (2005), US-Indonesia Military relationship, NY (USA): Council for Foreign Relations.

Pohan, R. (2001), Menjaga Jembatan Jakarta - Washington:Dubes Dorodjatun Kuntjoro-Jakti 1998-2001, Washington DC, penerbit tidak ada.

Rosenau.,J. ed, (1980),International

Politics and Foreign Policy, NY and London: Collins Mcmilan,

Simamora, P. (2013), Peluang dan Tantangan Diplomasi

Pertahanan, Jogjakarta: Graha Ilmu
Setiadji A. (2016),Alutsista dan Poros Maritim

Dunia,

Jakarta:Indotech

Serafino, N. (2007), Global Peace Operations Initiative: Background and Issues for Congress, 11 June 2007, Washington DC, US:CSR publication.

Sullivan, A.(2014),Strengthening US and Indonesia Defense Ties (paper), Washington DC: CNAS

Syawfie, I. (2009), Aktivitas Diplomasi Pertahanan Indonesia dalam Pemenuhan Tujuan Tujuan Pertahanan (2003-2008): tesis S2 Universitas Indonesia

Sukadis, B. (2011), Kebijakan Luar Negeri Australia dalam Normalisasi Kerjasama Pertahanan RI dan Australia, Jakarta: UPN Veteran Jakarta. Sukadis, B. (2013), Indonesia and US Defense Relations, in readingPost Hegemonic Global Governance, Amherst, MA, USA: ITD.

Supriyatno, M. (2014), Tentang Ilmu Pertahanan, Jakarta: Yayasan Obor 
Swistek, G. (2012), The Nexus between Public Diplomacy and Military Diplomacy in Foreign Affairs and Defense Policy; Vol. XI/No. 2 Spring 2012: Connections: The Quarterly Journal.

Vaughn, B. (2011), Indonesia: Domestic, Strategic Dynamic and US Interests, Washington DC: Congressional Research Service (CSR)

Weldes, J. (1996), Constructing National Interest: No. 2: Sage: European Journal of International Relations.

Widjajanto, A. dan Keliat, M. (2008), Reformasi Ekonomi Pertahanan Indonesia, Jakarta: INDEF

The 9/11 Commission Report Final report of the National Commission on Terrorist Attack upon the US; New York; WW Norton; 2003.

Tim LIPI, eds. (2001), Bara dalam Sekam: Identifikasi Akar Masalah dan Solusi bagi konflik-konflik Lokal di Aceh, Maluku Papua dan Riau, Jakarta: LIPI
Laporan Resmi dan Produk Strategis

Laporan Pelaksanaan IUSSD VIII, Juni 2010, Kemhan.

Kronologis Singkat Kegiatan IUSSD, 17 April 2012, Subdit Athan, Ditkersin, Direktorat Jenderal Strategi Pertahanan, Kementerian Pertahanan

Laporan Pelaksanaan IUSSD ke-10 dan JCM ke-3 di AS. Kemhan, 2012.

Laporan Pelaksanaan IUSSD ke-XI; Kemhan, Jakarta, 2013

Laporan Hasil Pelaksanaan IndonesiaUS Security Dialogue (IUSSD) XII tahun 2014; Kemhan, 2015.

Kerjasama Bidang Pertahanan, Kemhan, Jakarta, 2010.

Sekilas Hasil-hasil Indonesia-US Strategic Dialogue, Kemhan; Jakarta, 2010.

Buku Strategi Pertahanan Indonesia, Dephan; Jakarta, 2007.

Buku Putih Pertahanan Negara 2008, Dephan, Jakarta, 2008.

Congressional Record, Military to Military Cooperation, No. S 735, Februari 2005. 
Sustaining US Global Leadership of 21th Century Defense": DoD, Washington, US 2012.

\section{Undang-Undang}

UUD 1945

UU No. 3 tahun 2002 tentang

Pertahanan Negara

UU No. 34 tahun 2004 tentang TNI

UU No.97 tahun 1999 tentang

Kementerian Luar Negeri.

\section{Daftar Singkatan}

ACSA : Acquisiton

and Cross Service Agreement

\section{ALP} : Aviation

Leadership Program

Armabar

Armada

Kawasan Barat

Armatim : $\quad$ Armada

Kawasan Timur

Alutsista : Alat Utama

Sistem Persenjataan

BDD Bilateral

Defense Dialogue
CARAT : Cooperation

Afloat and Readiness Training

\section{CISMOA}

Communication and Information

Security Memorandum of

Agreement

CTFP

Combating

Terrorism Fellowship Program
: Departemen

Pertahanan

DHS : Department of

Homeland Security

DoD

: Department of

Defense

DoS

: Department of

State

DRM

: Defense

Resources Management

FMS

Foreign

Military Sales

FMF Foreign

Military Financing 
GPOI : Global Peace $\quad$ MoD $\quad$ : Ministry of

Operation Initiative

Defense

HADR : Humanitarian NDU : National

Assistance and Disaster Relieve Defense University

IMET : International ODA : Office of

Military Education and Training Defense Attachẻ

IMSS : $\quad$ Integrated $\quad$ ODC : Office of

Maritime Surveillance System Defense Cooperation

INL $\quad$ : International $\quad$ OMP $\quad$ : $\quad$ Operasi

Narcotics and Law Enforcement Militer Perang

Affairs

OMSP : Operasi

IUSDD $\quad$ : Indonesia Militer Selain Perang

United States Strategic Defense

Dialogue

Pothan

Potensi

Pertahanan

JCET : Joint

Combined Exercises Training

Strahan

Strategi

Pertahanan

Jakumhanneg : Kebijakan

Umum Pertahanan Negara

Renhan

Pertahanan

Kemhan : Kementerian

Pertahanan

TNI

Tentara

Nasional Indonesia

MEF : Minimum

Essential Forces 


UNHAN : Universitas

Pertahanan

USCG : US Coast

Guard

USPACOM : US Pacific

Command

USARPAC : US Army

Pacific Command 